\title{
Treatment of systemic hypertension is important for improvement of macular edema associated with retinal vein occlusion
}

This article was published in the following Dove Press journal:

Clinical Ophthalmology

16 May 2014

Number of times this article has been viewed

Teruyo Kida

Seita Morishita

Keigo Kakurai

Hiroyuki Suzuki

Hidehiro Oku

Tsunehiko Ikeda

Department of Ophthalmology, Osaka Medical College, Osaka, Japan

Correspondence:Teruyo Kida Department of Ophthalmology, Osaka Medical College, 2-7 Daigakumachi, Takatsuki, Osaka 569-8686, Japan Tel $+8 \mid 72683$ I22।

$\mathrm{Fax}+8|7268| 8195$

Email kidateruyo@gmail.com
Background: We report our findings in three cases of unilateral macular edema associated with retinal vein occlusion (RVO) that improved after successful treatment of systemic hypertension alone.

Methods: All three cases had systemic hypertension but no diabetes mellitus or other ocular diseases associated with macular edema. All patients were treated only with medication for systemic hypertension. Optical coherence tomography was performed to determine the foveal thickness before and after treatment.

Results: Case one was a 72-year-old woman with a central RVO who had macular edema in her left eye and a visual acuity (VA) of 20/50. Her blood pressure (BP) was 169/96 mmHg. One month after the initiation of a calcium blocker to treat her systemic hypertension, her BP was decreased, macular edema was reduced, and her VA improved to 20/20. Case two was a 62-year-old woman with branch RVO. Her VA was 20/40 and her BP was 165/97 mmHg. Six weeks after initiation of medication to treat her systemic hypertension, her RVO-related macular edema had decreased and her VA improved to 20/20. Case three was a 71-year-old man with branch RVO. His VA was 20/50 and his BP was $165 / 87 \mathrm{mmHg}$. One month after initiation of treatment for systemic hypertension, his RVO-related macular edema had disappeared and his VA improved to 20/20. All three cases had nonischemic RVO by fluorescein angiography, and they did not develop ischemic changes for at least 1 year.

Conclusion: The reduction of macular edema following a decrease in the systemic hypertension suggests that the edema was most likely caused by leakage of fluids from the blood vessels. We recommend that the blood pressure should be measured in all patients with macular edema before initiating intravitreal anti-VEGF therapy.

Keywords: anti-VEGF therapy, early treatment, frequent injection, high cost

\section{Introduction}

Intravitreal injections of antivascular endothelial growth factor (anti-VEGF) are currently the standard treatment of macular edema related to retinal vein occlusion (RVO), eg, by an intravitreal injection of either ranibizumab or aflibercept. ${ }^{1}$ These treatments are also effective in achieving a relatively rapid resolution of macular edema in most RVO patients. ${ }^{1,2}$ The visual acuity (VA) is improved, and there are few complications. However, repeat injections are often required because of a recurrence of macular edema, which increases the risks associated with intravitreal injections. ${ }^{1}$

We report our findings in three cases of macular edema secondary to a unilateral RVO, where the macular edema was reduced by treating only an existing systemic hypertension. VA also improved, and there were no recurrences for at least 1 year. 


\section{Cases}

Case one was a 72-year-old woman with a central RVO (CRVO), who had macular edema in her left eye, with a VA of 20/50. Her blood pressure (BP) was 169/96 mmHg, and she did not know that she had systemic hypertension. We recommended that she be examined by an internist, who diagnosed her with systemic hypertension and prescribed antihypertensive medications. One month after the initiation of a calcium antagonist, her BP had decreased to around 135/80 mmHg, and her RVO-related macular edema had disappeared (Figure 1). In addition, her VA had improved to 20/20, and her foveal thickness (FT) measured by optical coherence tomography (Spectralis, Heidelberg, Germany) decreased from $550 \mu \mathrm{m}$ to $241 \mu \mathrm{m}$. Her retinal hemorrhages had disappeared, and there has been no recurrence of the macular edema for at least 1 year.

Case two was a 62-year-old woman with a branch RVO (BRVO) in her left eye. Her VA was 20/40 and her BP was $165 / 97 \mathrm{mmHg}$. Six weeks after beginning an angiotensin II blocker to treat her systemic hypertension, her BP decreased to $131 / 78 \mathrm{mmHg}$, her VA improved to $20 / 20$, and her RVOrelated macular edema had decreased, with the FT reduced from $532 \mu \mathrm{m}$ to $225 \mu \mathrm{m}$ (Figure 2).

Case three was a 71-year-old man with BRVO in his right eye. His VA was 20/50 and his $\mathrm{BP}$ was $165 / 87 \mathrm{mmHg}$. One month after initiation of a combination of a calcium blocker and angiotensin receptor blocker, his BP decreased to $135 / 81 \mathrm{mmHg}$, his VA improved to $20 / 20$, and his RVOrelated macular edema was not present (Figure 3). The FT was reduced from $321 \mu \mathrm{m}$ to $213 \mu \mathrm{m}$. His BRVO improved, and there has been no recurrence of the macular edema for at least 1 year and 9 months.

In all three cases, the RVO-related macular edema was improved or completely resolved following treatment of the systemic hypertension alone. All of the cases had nonischemic RVO by fluorescein angiography, and they did not progress to ischemic changes after the treatments. There have been no recurrences of macular edema, and good VA was maintained for at least 1 year.

\section{Discussion}

In all three cases of RVO-related macular edema, there was an improvement or complete resolution of the edema following treatment of an existing systemic hypertension alone. Importantly, the VA was improved and an intravitreal injection of anti-VEGF was not needed. There were no recurrences of macular edema during our observation period of at least 1 year.

It is known that the RVO-related macular edema responds well to intravitreal anti-VEGF because the predominant cause of macular edema is the high levels of VEGF. ${ }^{3}$ However, frequent injections of anti-VEGF antibodies are required,
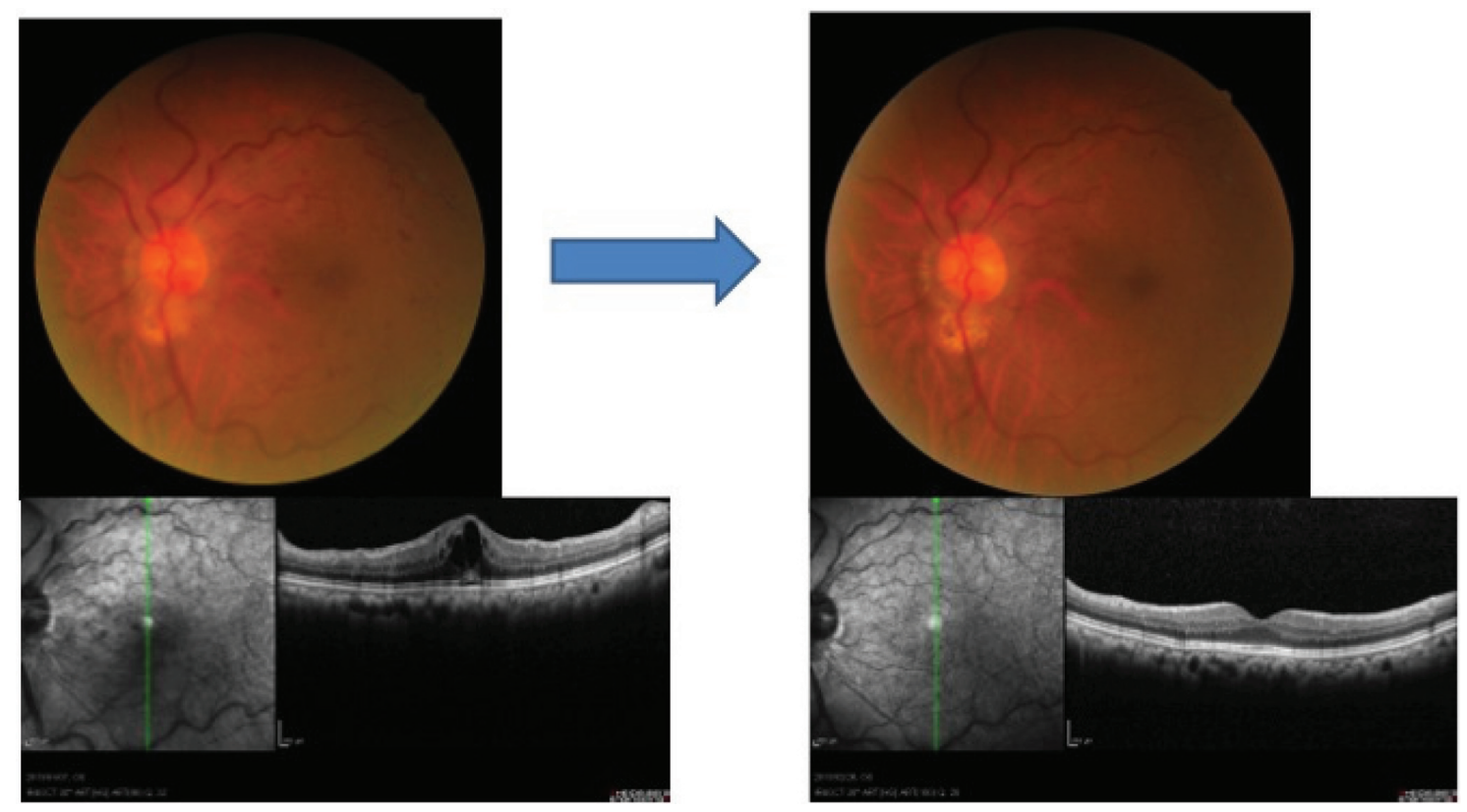

Figure I Case one: fundus and optical coherence tomographic images of a 72-year-old woman with a CRVO before and after treatment of systemic hypertension with a calcium blocker.

Notes: At the first visit her BP was $169 / 96 \mathrm{mmHg}$ with no medications, and her fundus showed an impending CRVO with macular edema. Her VA was 20/50. One month after the treatment of systemic hypertension, her macular edema completely disappeared, and her VA was improved to 20/20 with no recurrence for at least I year. Abbreviations: BP, blood pressure; CRVO, central retinal vein occlusion; VA, visual acuity. 

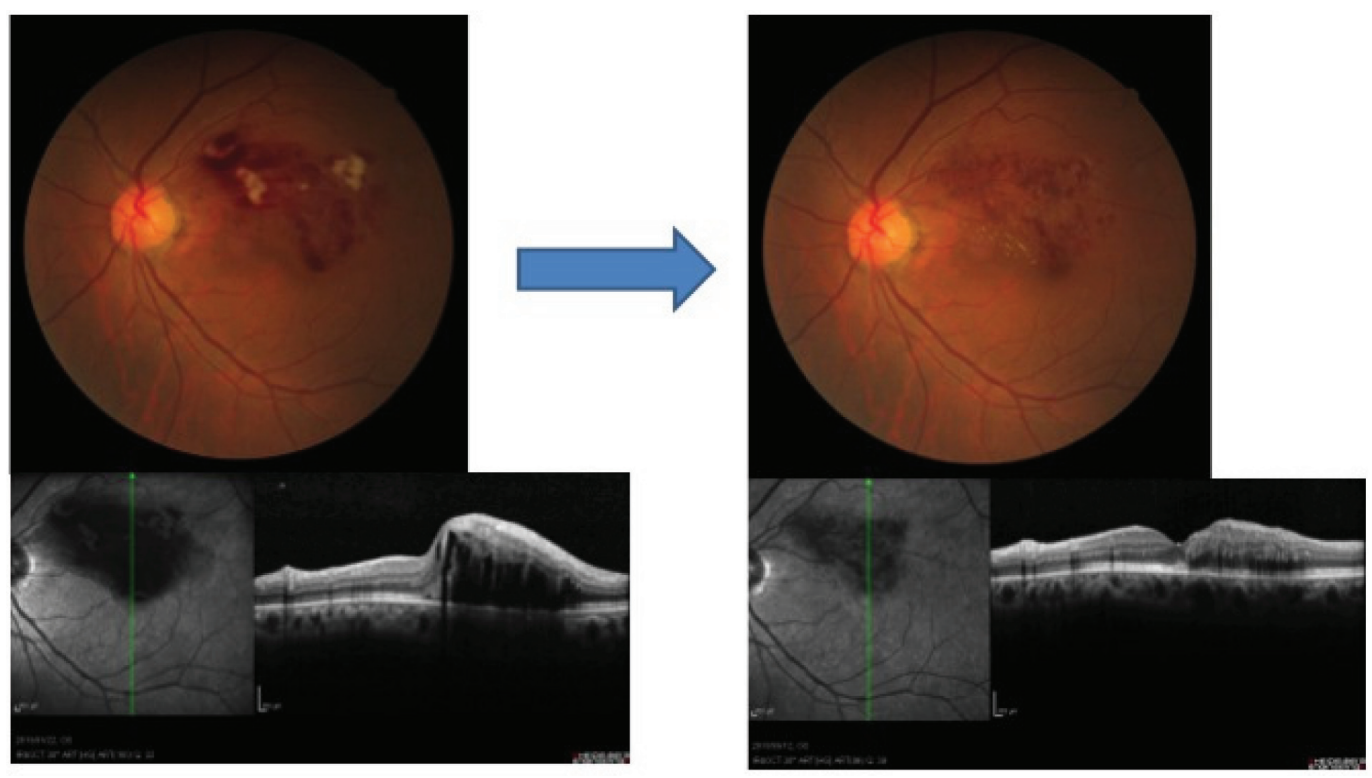

Figure 2 Case two: fundus and optical coherence tomographic images of a 62-year-old woman with BRVO before and after treatment of her systemic hypertension with an angiotensin II blocker.

Notes: Her BP was 165/97 mmHg at the first visit. Macular edema decreased, and her VA improved from 20/40 to 20/20 after treatment. Abbreviations: BP, blood pressure; BRVO, branch retinal vein occlusion; VA, visual acuity.

and it is still not known exactly how many intravitreal injections can be tolerated by an eye. In addition, the high cost of VEGF inhibitors is a significant problem. ${ }^{4-6}$ Thus, it would be efficacious to treat macular edema by other techniques or drugs.

Our findings indicate that we should not only ask the patients if they have systemic hypertension but also measure the blood pressure, as our first patient was not aware she was hypertensive. If the patient has systemic hypertension, we should advise them to see a doctor of internal medicine to treat the systemic hypertension prior to any intravitreal injection of anti-VEGF medications.

Systemic hypertension can cause damage to blood vessels of the retina, eg, hemorrhages, cotton wool spots, and macular edema. Retinal vascular changes are associated with hypertension and diabetes and can predict cardiovascular events. ${ }^{7}$
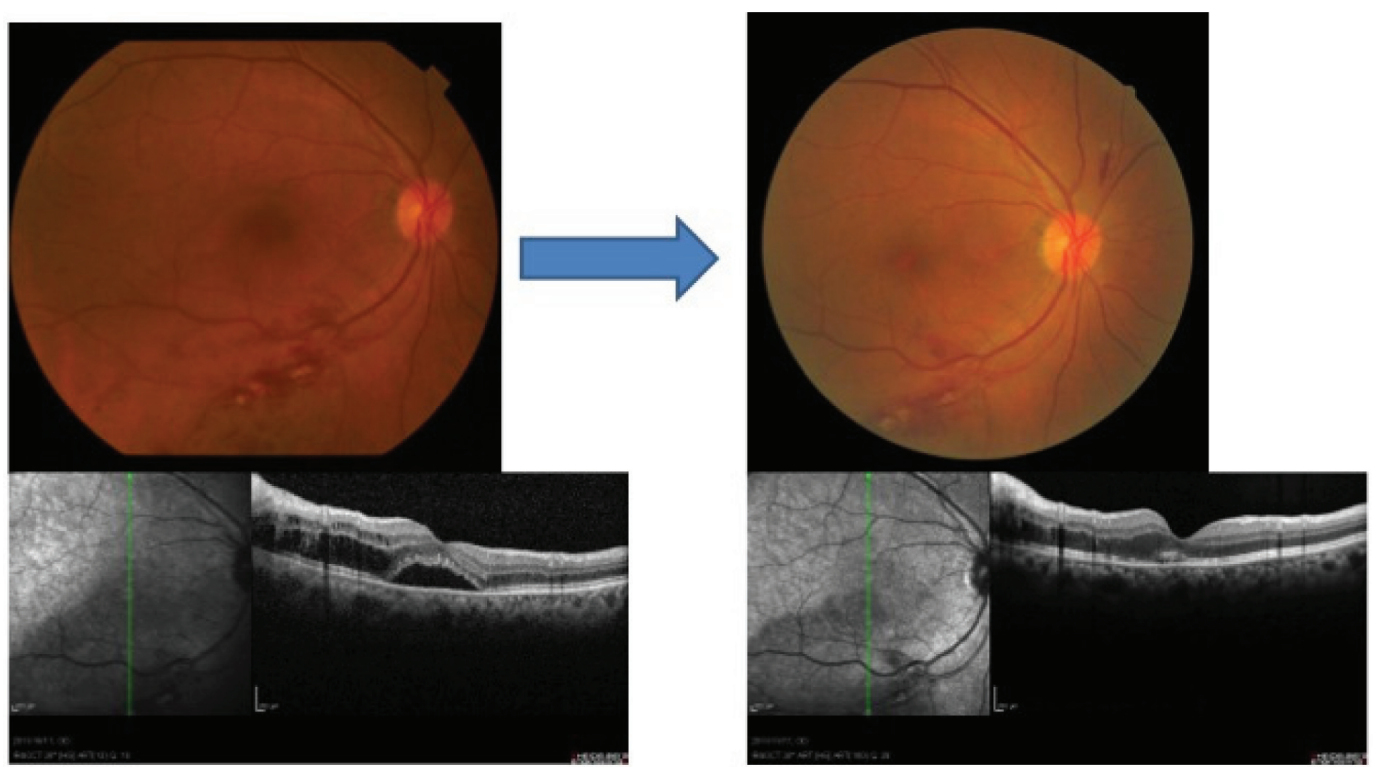

Figure 3 Case three: fundus and optical coherence tomographic images of a 7I-year-old man with a BRVO before and after treatment of systemic hypertension with angiotensin receptor blocker.

Notes: His BP was $165 / 87 \mathrm{mmHg}$ at the first visit. Macular edema was not present with greatly improved VA from 20/50 to 20/20 I month after treatment. Abbreviations: BP, blood pressure; BRVO, branch retinal vein occlusion; VA, visual acuity. 
Relevant to our cases, CRVOs and BRVOs are both associated with macular edema. Other major predisposing factors for macular edema are diabetes, dyslipidemia, smoking, and renal disease. ${ }^{7,8}$ Identifying and treating any systemic diseases should be done to reduce the risk of developing macular edema and also prior to any anti-VEGF injections.

Martínez et al reported that a RVO may be the first manifestation of undiagnosed hypertension. ${ }^{9}$ Therefore, the early detection of hypertension and good control of BP levels may prevent a RVO. ${ }^{9}$ As ophthalmologists, we should be much more careful in determining whether systemic hypertension is present in patients with a RVO.

However, we must remember that VEGF inhibition for RVO-related macular edema is more effective in reducing macular edema and improving VA if performed within 3 months after onset. This suggests that beginning the treatment 3 months after onset would probably be too late. ${ }^{10,11}$ Thus, if an initial alternate therapy is tried, the results need to be obtained in less than 3 months. Early treatment is important in CRVO because the natural course of the visual functions is particularly poor in CRVO as opposed to BRVO. ${ }^{12,13}$ It has been reported that untreated eyes with CRVO generally have poor VA, which decreases with time, and one-fourth of eyes with nonischemic CRVO converted to ischemic CRVO. ${ }^{12}$ In our three cases, macular edema was improved within 4-6 weeks after onset with medications only for the systemic hypertension. Even if the macular edema recurred, we would still have had time to administer anti-VEGF therapy.

There are limitations of this study. We studied only three patients, and there were no controls; therefore, further investigation with controls is required. However, we present our findings so that others can determine if similar findings can be made in a larger number of patients.

In conclusion, our findings show that the blood pressure of patients with macular edema associated with a RVO should be measured before anti-VEGF therapy is instituted. If systemic hypertension is present, it should be treated before any anti-VEGF therapy is begun.

Clinical Ophthalmology

\section{Publish your work in this journal}

Clinical Ophthalmology is an international, peer-reviewed journal covering all subspecialties within ophthalmology. Key topics include: Optometry; Visual science; Pharmacology and drug therapy in eye diseases; Basic Sciences; Primary and Secondary eye care; Patient Safety and Quality of Care Improvements. This journal is indexed on Submit your manuscript here: http://www.dovepress.com/clinical-ophthalmology-journal

\section{Acknowledgment}

The authors deeply thank Professor Duco Hamasaki for discussions and editing assistance.

\section{Disclosure}

The authors report no conflicts of interest in this work.

\section{References}

1. Pielen A, Feltgen N, Isserstedt C, Callizo J, Junker B, Schmucker C. Efficacy and safety of intravitreal therapy in macular edema due to branch and central retinal vein occlusion: a systematic review. PLoS One. 2013;8(10):e78538.

2. Glanville J, Patterson J, McCool R, Ferreira A, Gairy K, Pearce I. Efficacy and safety of widely used treatments for macular oedema secondary to retinal vein occlusion: a systematic review. BMC Ophthalmol. 2014;14:7.

3. Campochiaro PA, Hafiz G, Shah SM, et al. Ranibizumab for macular edema due to retinal vein occlusions: implication of VEGF as a critical stimulator. Mol Ther. 2008;16(4):791-799.

4. Haller JA. Current anti-vascular endothelial growth factor dosing regimens: benefits and burden. Ophthalmology. 2013;120(5 Suppl): S3-S7.

5. Smiddy WE. Clinical applications of cost analysis of diabetic macular edema treatments. Ophthalmology. 2012;119(12):2558-2562.

6. Stein JD, Newman-Casey PA, Mrinalini T, Lee PP, Hutton DW. Cost-effectiveness of bevacizumab and ranibizumab for newly diagnosed neovascular macular degeneration. Ophthalmology. 2014;121(4):936-945.

7. Katsi V, Marketou M, Vlachopoulos C, et al. Impact of arterial hypertension on the eye. Curr Hypertens Rep. 2012;14(6):581-590.

8. O'Mahoney PR, Wong DT, Ray JG. Retinal vein occlusion and traditional risk factors for atherosclerosis. Arch Ophthalmol. 2008;126(5):692-699.

9. Martínez F, Furió E, Fabiá MJ, et al. Risk factors associated with retinal vein occlusion. Int J Clin Pract. Epub Feb 18, 2014.

10. Bhisitkul RB, Campochiaro PA, Shapiro H, Rubio RG. Predictive value in retinal vein occlusions of early versus late or incomplete ranibizumab response defined by optical coherence tomography. Ophthalmology. 2013;120(5):1057-1063.

11. Kondo M, Kondo N, Ito $\mathrm{Y}$, et al. Intravitreal injection of bevacizumab for macular edema secondary to branch retinal vein occlusion: results after 12 months and multiple regression analysis. Retina. 2009;29(9):1242-1248.

12. McIntosh RL, Rogers SL, Lim L, et al. Natural history of central retinal vein occlusion: an evidence-based systematic review. Ophthalmology. 2010;117(6):1113-1123.e15.

13. Hayreh SS, Zimmerman MB. Branch retinal vein occlusion: natural history of visual outcome. JAMA Ophthalmol. 2014;132(1):13-22.
PubMed Central and CAS, and is the official journal of The Society of Clinical Ophthalmology (SCO). The manuscript management system is completely online and includes a very quick and fair peer-review system, which is all easy to use. Visit http://www.dovepress.com/ testimonials.php to read real quotes from published authors. 